\title{
Management of Concurrent Engineering Processes in international product development
}

\author{
Uwe F. Baake \\ debis-humaitá, HPTD, Al. Campinas, 1070 - Jd. Paulista \\ São Paulo - SP - Brasil, CEP 01404-002 \\ Tel.: +55118862925 - Fax: +55118862824 \\ email:baake@compuserve.com
}

Dieter E. Haussmann

debis-humaitá, HIPD, Al. Campinas, 1070 - Jd. Paulista

São Paulo - SP - Brasil, CEP 01404-002

Tel.: +55118862779 - Fax: +55118862801

email: haussmann@hitnet.com.br

\begin{abstract}
The globalization of markets does not only create new business opportunities but also challenge by new, worldwide competition. As a result there is a need to reduce product development times, to realize highly concurrent engineering processes and to integrate company-wide resources as well as local and global suppliers. Such processes require highly skilled experts, fast and stable procedures and lean and flexible organizations. This report illustrates the introduction of new methods and tools for engineering, allowing faster and higher integrated development and production processes within an international environment. First experiences of the proposed methods will be briefly outlined in this approach and have already been proved in Europe and Southern America.
\end{abstract}

Keywords

Global Product Development, Product Data Management, Practical applications and experiences 


\section{INTRODUCTION}

As outlined in Figure 1 the various divisions of the Daimler-Benz Company are distributed all over the world. International job-sharing as part of such a global network and co-operation leads to products which make optimum use of the resources which exist locally. For Daimler-Benz the introduction and optimization of global distributed product development is becoming the most important factor to improve competitiveness and takes place in front of an ongoing reduction of product development cycles, decentralization and increasing globalization.

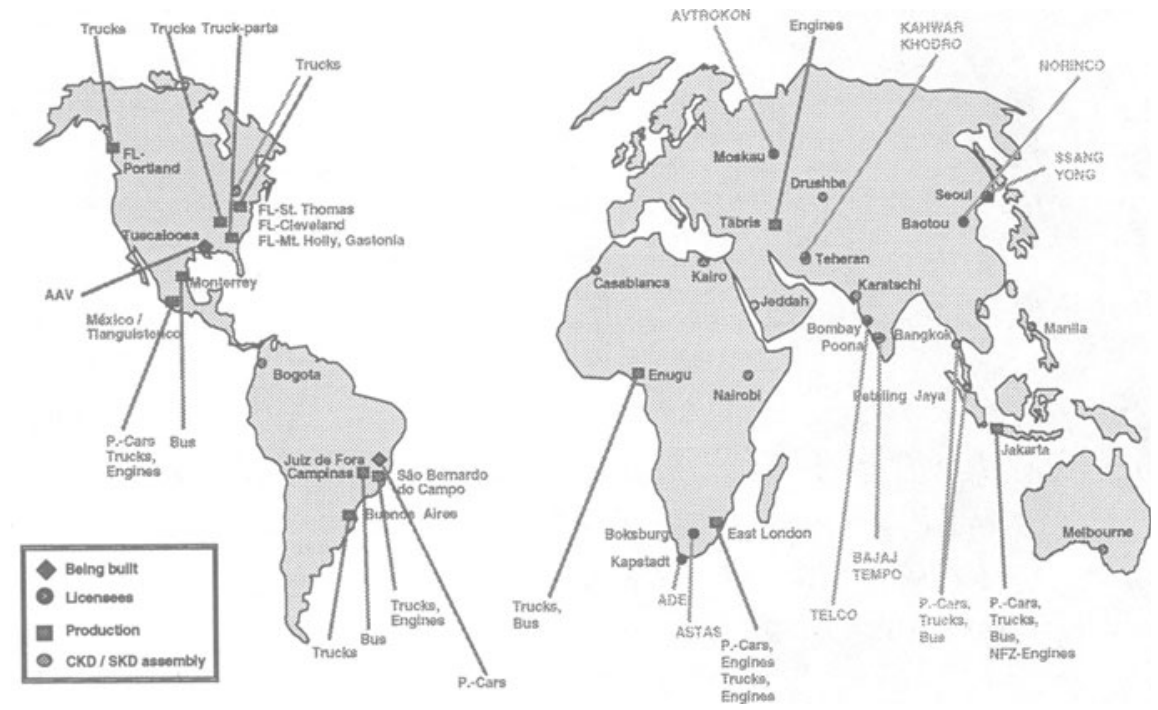

Figure 1 Global network of Daimler-Benz AG development and production sites outside from Europe

The introduction of new structures and implementation of efficient product development concepts, requires fast and consequent implementation of Simultaneous Engineering (SE), Engineering Data Management (PDM), Digital Mock-Up (DMU), the integration of geometry and Bills of material (BOM) together with a business process oriented information processing and Processmanagement with Master Plan technique and Gateway-Controlling. In this context, new processes, the integration of suppliers in the development process as well as enhanced computer capabilities and high-speed data networks are changing the world of engineering dramatically (Baake,Haussmann,Stratil, 1997). Concurrent Engineering (CE) as a synonym for new engineering approaches, processes, tools, methods and complex technical systems is one of the key-factors 
for the emerging next step of the industrial revolution initiated by information technology and globalization.

This approach illustrates the first steps of the introduction of concurrent engineering processes within a global world-wide distributed enterprise and discuss the preconditions and problems resulting from such an international collaboration. Based on our experiences in various vehicle projects, developed by complex processes - distributed across time, participants and functional perspectives (Baake,Stratil, 1997) we outline a new general concept for the integration of the Brazilian and German sites of the Daimler-Benz commercial vehicles division as well as their different partners and suppliers into common simultaneous engineering processes. Hence, e.g. an efficient digital communication platform, has to be introduced. Using a customized Product Data Management (PDM) system all different systems and data might be integrated during the complete product life cycle as outlined in Figure 2.

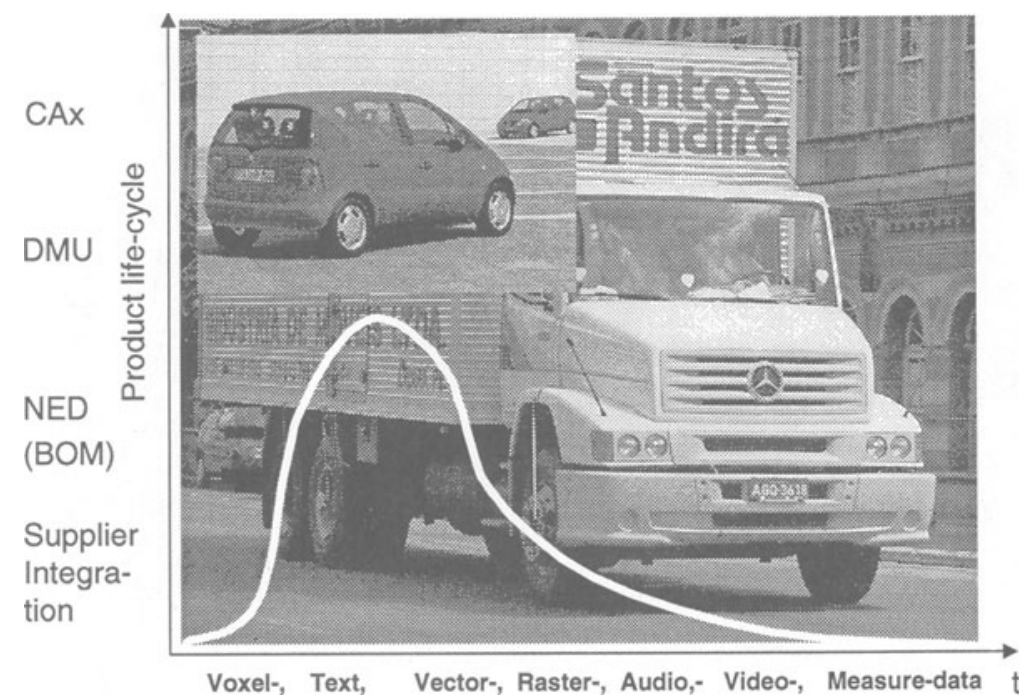

Figure 2 PDM integrates systems and data during the complete product life-cycle

This presentation illustrates various aspects resulting from an international cooperation in a practical manner and shows, how we are solving these problems in a partnership between Germany and Brazil by leading to more general solutions. Following a general globalization strategy overview, inefficiencies in current product development processes are given in Section 3. Section 4 then describes our optimization methodology of these processes. Section 5 discusses the introduction of Product Data Management in a world-wide environment. In Section 6, preconditions and problems of the introduction of Simultaneous Engineering in multi-cultural, interdisciplinary cooperation with respect to e.g. human and cultural factors, legal aspects, different time zones, etc. are outlined. 


\section{GENERAL GLOBALISATION STRATEGY}

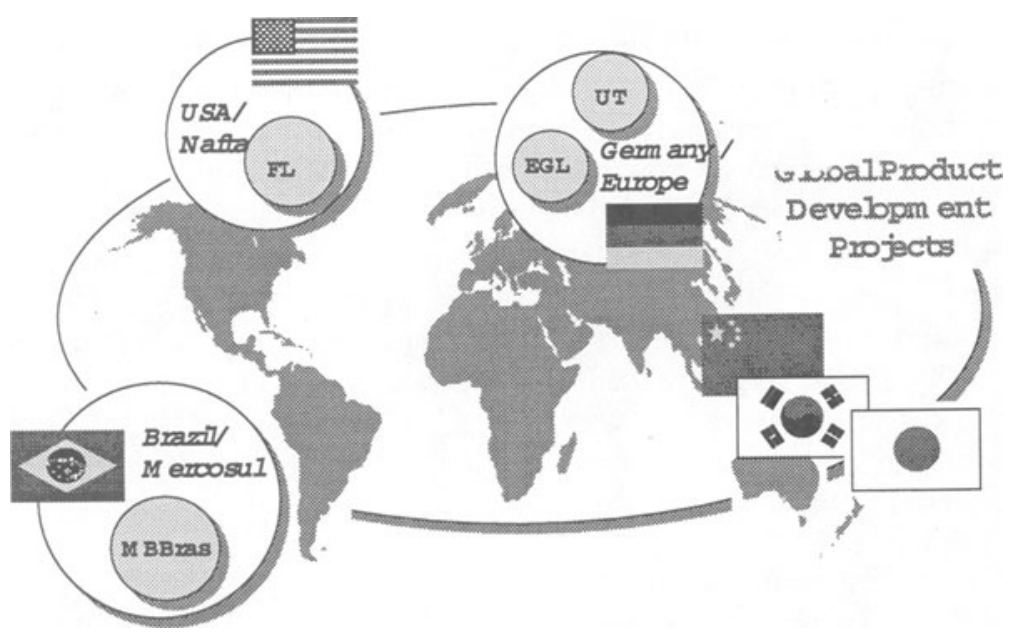

Figure 3 Different globalization levels

For its globalization process the commercial vehicles division uses a general strategy which requires specific skills, knowledge and resources to implement regional-specific processes on three different levels as outlined in Figure 3. On the first level processes specific to the different Daimler-Benz locations will be detailed. The next level includes regional processes between one of the outlined locations and the relevant local partners and suppliers, e.g. suppliers in Europe, Nafta or Mercosul respectively. Finally the high-level inter-company processes are implemented to connect the mentioned Mercedes-Benz locations and other highly qualified partners throughout the world. Purposes of this worldwide network include the ability to serve different markets even better or to produce and develop basic components at the most appropriate location. Communication with the various parties involved, is an important element in international cooperation projects, partnerships and suppliers relationships (Kesteloot, 1995) (Shu,Flowers, 1994). Therefore it is necessary to maintain control of e.g. information technology or project team organization and resource profiling.

\section{INEFFICIENCIES IN STATE OF THE ART PRODUCT DEVELOPMENT PROCESSES}

Based on practical experience from projects on three different continents we analyzed the efficiency of our current product development processes (Stratil, Hausin,Baake, 1998). We found inefficiencies resulting from general existing 
problems of concurrent, co-operative product development on both, in-company as well as inter-company processes. It points out that apart from necessary introduction of sophisticated information-technology and working-methodology also the companies strategic framework, the commitment of the management and the qualification of the stuff plays a dominant role for site-specific process optimizations (Champy, 1995). The globalization of companies has considerably changed over the past couple of years. Instead of buying or building new partner companies, cooperation with global partners or even with former competitors will be created. This cooperation may lead to benefits with more overall flexibility, wider ranges of products, bigger market-shares and faster and cheaper product development. Achieving all these benefits it is necessary to harmonize intercompany processes based on both, technical aspects and soft-factors to be able to put the different skills of the companies' experts together and get an added value on the results of cooperative work.

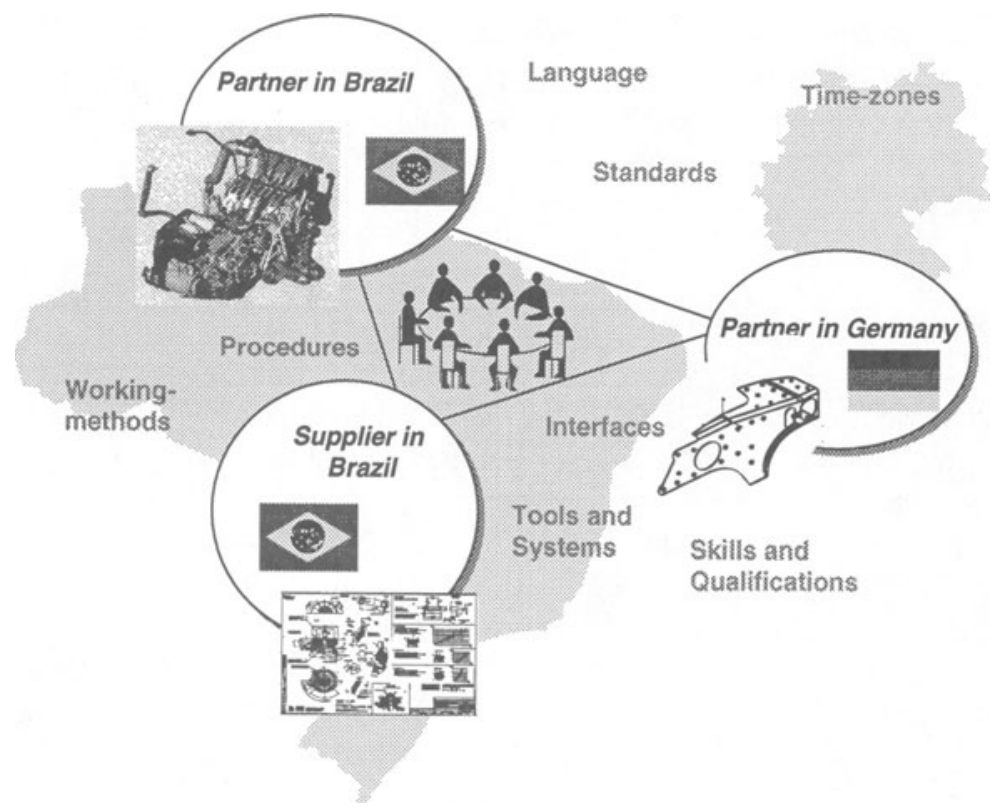

Figure 4 Global cooperation requires concurrent work and elimination of retarding factors for efficient inter-company processes.

This fact is illustrated in Figure 4 and points out some retarding factors for smooth concurrent processes between global partners. Some of the outstanding topics which influence the process-efficiency fundamentally are:

- standards: national and regional differences 
- procedures: change management, parts release, etc.

- tools and systems: CAD and BOM-systems, etc.

- working methods: paper drawings or digital mock-up

- interfaces: loss/distortion of exchanged information

- language: misunderstanding, equivocation

- time-zones: no overlapping working hours

- qualification: not adequate, not up-to-date, etc.

First attempts to set-up concurrent product development on the level of intercompany processes led to problems since co-operations goals could not be reached. Many times it was not possible to finish projects within a predefined time and costs-schedule although big efforts were undertaken to improve intercompany processes. The objective was to eliminate the identified retarding factors. Yet, final detailed analyses proved the fact that the effectiveness of cooperative work was not preliminary based on inter-company processes.

The more time and cost-consuming problems could be found internally within the companies, which were supposed to work together. The in-company processes for product development are broken into single parts because of a lack of communication between functional organizational units and the lack of a consistent product language throughout the entire development phase.

\section{OPTIMIZING PRODUCT DEVELOPMENT PROCESSES}

In (Stratil,Hausin,Baake, 1998) our general methodology for concurrent engineering process optimization is presented. Adapting this general concept, which is valid for in-company and inter-company processes as well, to MercedesBenz Brazil, we will focus in this approach on our first results and experiences.

The introduction of Simultaneous Engineering (SE) with the purpose of replacing old sequential structures and process forms with simultaneous, interdisciplinary cooperation was identified as one of the key-factors in optimizing existing development processes. This stresses management and organizational aspects and includes multi-cultural and worldwide-distributed interdisciplinary team working as well.

As the second key-factor the introduction of Product Data Management (PDM) as a general communications platform for the structured storage of product information and for the security of global workflows was recommended. This part is more technical oriented and includes the implementation of basic infrastructure. Systems and tools for geometry and data management (e.g. CATIA, GIS, and Metaphase/Smaragd) as well as for group interaction (e.g. Intranet, Lotus Notes) and data transfer (e.g. SWAN - System for worldwide exchange of product data) has to be selected. 
The final key-factor identified in (Stratil,Hausin,Baake, 1998) is a Projectmanagement with Master Plan technique and Gateway-Controlling (PMG) for the transparent execution of development projects. In Brazil we introduced a multi-cultural Process-Management team for the general control of PMG. The main activities in respect to PMG are under control of the different product development projects and their leaders.

In the following we will focus on the first and the second key-factor in process optimization, i.e. the introduction of SE and PDM. Adapting our general concept to Mercedes-Benz Brazil and considering the analysis results from Section 2, we started the introduction of new and efficient simultaneous engineering processes with the first steps of a PDM communications platform implementation.

Referring to our situation in Brazil we first elaborated a general 3-phases introduction plan which could be adapted to the corresponding partner. The so called " 3 phases-concept" is the consulting strategy of ODN/S (dept. of the central organization and data engineering area of Daimler-Benz AG commercial vehicles division in Germany) to implement new, high- level processes. Thus we enable our business-units to communicate efficiently in global cooperation with international partners. The different phases of this plan include:

\section{Project definition \\ 4-6 months \\ 2. Site specific introduction concept \\ 6-8 months \\ 3. Supported pilot-phase 8-12 months}

After these phases a site-wide realization will be done with staff from the corresponding country. At Mercedes-Benz Brazil we used this concept and started in early 1996 with the project definition phase as outlined in Figure 5.

In the next phase, started in the middle of 1996 a general site-specific concept for process-fitness was elaborated (Baake,Stratil, 1997). The third phase, which started in April 97 and finished at the end of 1997 prototypes of the required systems, tools and methods were implemented and evaluated by the Brazilian staff. German tasks in this phase were reduced to support activities. During the realization phase from 1998 until 1999 as depicted in Figure 5 our PDM communication platform will be integrated into the whole product development process chain and the new methods, like e.g. 3D Digital Mock-up processes, new product documentation or efficient partner and supplier integration will be introduced and used in different product development projects between Mercedes-Benz Brazil and different partners and suppliers. The results of the finished 3 phases were:

- Mercedes-Benz Brazil got a role as a global development player within the commercial vehicles division of Daimler-Benz AG. 
- The central consulting team in Germany got results and experiences from their first "reference project" and is supporting MBBras/debis-humaitá to maintain a unique strategy.

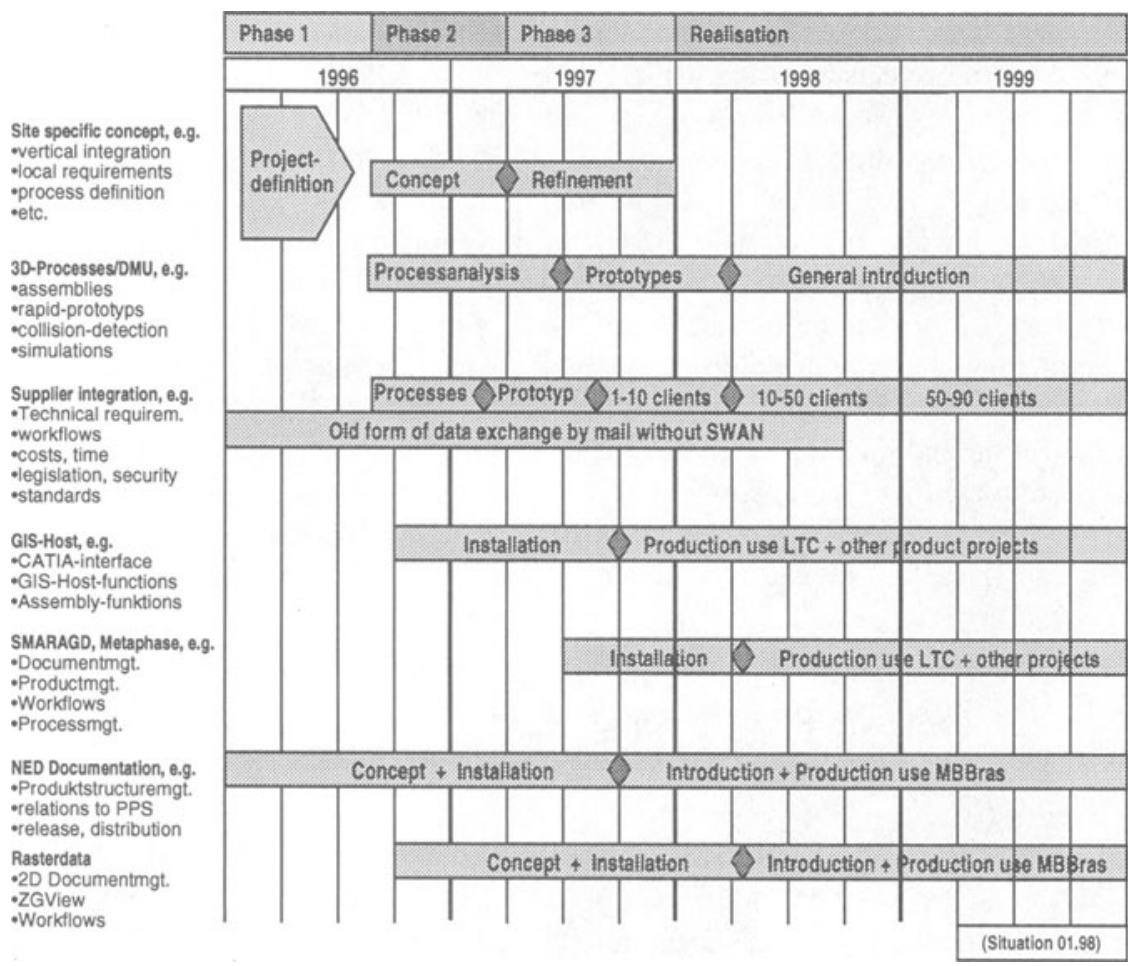

Figure 5 General 3-phases introduction concept

After presenting an overview about the general consulting strategy in the following we will outline more detailed some results and experiences from PDM and SE introduction.

\section{PRODUCT DATA MANAGEMENT INTRODUCTION}

Ensuring that the various parties involved in a common product development process are able to communicate with each other is an important element in international cooperation (Subrahmanian, 1995). Development cycles can be significantly shortened and products launched more rapidly by using PDM systems for integrated product data management or systems to control and partially automate business processes. 
An efficient communication among all project participants should be provided through the introduction of a unique product language. Each and every product information existing in different media at different times should be stored in a structured form so that it can be available to all process participants at any time. The SE teams will be able to document their project progress through the introduction of a PDM platform and include functional organizations in the project work. Modern PDM systems, such as the one customized by Daimler-Benz AG (i.e. SMARAGD) provide worldwide remarkable Client/Server Architecture enabling a time/site-independent cooperation. This way, a global concurrent product development will be enabled.

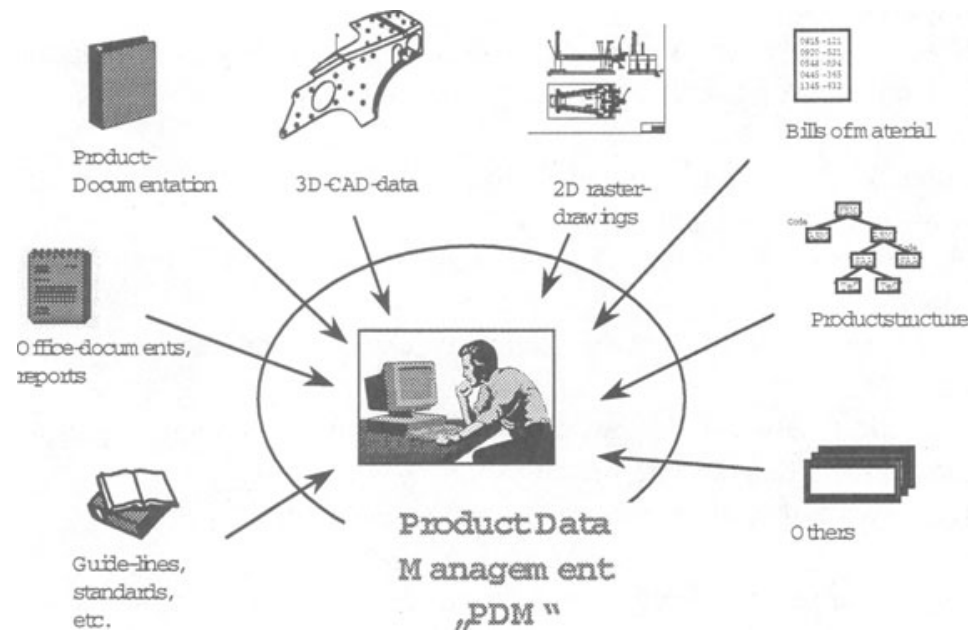

Figure 6 Product Data Management

In this context, two approaches should be considered. First, the product is developed using entirely new methods without taking into account existing systems. Second, the product is developed also using existing systems, simultaneously demanding maximum possible migration towards new engineering methods, adapted to the more conservative methods.

In the first case, many problems in setting up a common communications platform and restructuring business processes could be avoided, without considering the existing system set-up. Instead, all development processes are formulated afresh. For suppliers and partners this involves considerable costs, in the upgrading of their systems and in the adaptation of their engineering methods. This process also includes the introduction of 3D Digital Mock-up (DMU), new product documentation (NED), product data management (Smaragd), etc. 
In the second case, new methods have to be integrated into existing system infrastructure. This applies in particular to the inclusion of worldwide development and production locations with different levels of industrial growth.

Summing up, when introducing the mentioned new development processes and systems a site-specific optimization-approach must be found.

To achieve a rapid market presence in a new product development, it is necessary to carry out an time/cost-oriented product development process. Expensive development activities in proportion to the aimed sales numbers should possibly be specified before the design start. Development expenditures, production costs and achievable sales results should be determined and submitted to be evaluated. In addition, the product's technical feasibility should be taken into account together with the first drawings. Increasing the complexity of our products this will become a very important factor.

In order to structure the product development process in an ideal manner, also organizational measures were applied:

- In-time and comprehensive description of the new product in an unique product language

- Early involvement of the Sales department in the definition phase of the product

- Personal responsibility for the technical feasibility and assurance throughout the development

- Cooperation between design, documentation and production planning with regard to simultaneous engineering

- Early involvement of development partners and suppliers

These targets apply to single company domains as well as to a worldwide distributed product development.

\section{SIMULTANEOUS ENGINEERING AND MULTI-CULTURAL, INTER-DISCIPLINARY COOPERATION}

In the following we will outline our experiences by focussing on language barriers, cultural differences and different time zones. At the beginning of our project we have defined a common language for personal communication, videoconferencing, for the preparation of documents, such as reports, guidelines and standards. Anyway for efficient communication in our opinion it is also necessary to have at least one native speaker of the corresponding other country in each team. Thus, one pre-requisite in selecting employees for international projects has to be language knowledge. In order to guarantee the permanent exchange of new ideas, results, etc., we use video-conferencing. Among language barriers cultural differences are an important factor in the success of international collaborations. 
The working methods are often quite different. In Germany, e.g. every problem solution requires a detailed planning phase while, for example in Brazil the solutions are more improvised. In e.g. Europe or the U.S. large projects are mostly organized in project structures outside hierarchical organizations and responsibilities while in other countries the project-responsibilities always correspond to the hierarchical organization of the company. Sensibility or punctuality is other cultural factors that have to be considered. Other preconditions and problems result from technical factors, such as differences in infrastructure, network protocols or HW/SW components. Special services are often not available in some locations or too expensive. Legal aspects are also very important when setting up such international collaboration.

Finally we briefly outline the problem resulting from different time zones, e. g. it is very difficult to find a common time slot for e.g. communication and co-ordination within an international cooperation between the U.S. (West coast), Brazil, Germany and Indonesia. Other problems caused by different time-zones in a project connected in an intercontinental net may Integrated database security, 24 hours support, Batch actualization, new releases, etc.

\section{CONCLUSIONS}

In this paper the global engineering strategy of the Daimler-Benz commercial vehicles division within a specified international collaboration is outlined. Therefore we discussed new processes and first experience with different methods, that together implement efficient simultaneous engineering within an international environment. In the near future it could be possible to imagine, an integrated $\mathrm{PDM} / \mathrm{DMU}$ system that would assemble features for design (style concept, ergonomic properties,...), functional analysis (mechanisms, stress, aerodynamics,..), manufacturing, project management, etc. Our recommendations for future work include first of all a stronger consideration of the human aspects as outlined in Section 6. Corresponding to international projects a precise planning phase considering the special preconditions of the involved countries is very important. This includes visits as well as the incorporation of employees with special working experiences in these countries. Before starting such a project a commitment of the top-management of each site is strongly emphasized. This has to include a definition of the financing because it is often not that easy to calculate and prove the profitability of such projects. Generally the ratios which we are expected by the introduction of the new processes and methodologies are first a faster production-start-off and second, the reduction of the number of physical prototypes. Third, fewer changes and problems during the start-off of the production and finally more stable processes. 


\section{REFERENCES}

Baake, U.; Haussmann, D. and Stratil, P. (1997) Desenvolvimento de produtos de nova geração em uma empresa automotiva, IX Simpósio de Engenharia Automotiva, São Paulo, Brazil.

Baake, U. and Stratil, P. (1997) Implementing concurrent engineering processes within an international environment, in Building Tomorrow's Virtual Enterprise (ed. K. Reger), SCS Publication.

Champy, J. (1995) Reengineering Management, Harper-Business.

Kesteloot, P. (1995) GEN Engineering in Practice, in Advances in Design and Manufacturing (Eds. K.R. von Barisani, P.A. MacConaill and K. Tierney).

Shu, L and Flowers, W. (1994) Teledesign: GroupWare user experiments in 3D CAD. Collaborative Computing, Vol. 1, pp. 1-14, Chapman \& Hall.

Stratil, P.; Hausin, J. and Baake, U. (1988) An efficient optimization technique for Concurrent Eng. Processes, in Concurrent Engineering: The Way Forward (Eds. U. Baake and R. Zobel), SCS Publication.

Subrahmanian, E. et al, (1994) Computer Based Support for Cooperative Work in Eng. Design and Manufacturing, in Advances in Agile Manufacturing.

\section{BIOGRAPHY}

Uwe Baake recieved the Dipl.-Ing. degree in electrical engineering from the University of Siegen in 1990, and the Dr.-Ing. degree in computer science from Darmstadt University of Technology in 1995, Germany. In 1990 he joined the Computer Science Department of Darmstadt University of Technology, working in the Computer Aided Design Area. From 1995 to 1998 Dr. Baake was member of the Daimler-Benz Exchange group, working in the Corporate Research of Daimler-Benz AG in Ulm, the headquarters of the Commercial Vehicles division in Stuttgart, and debis humaitá IT Services Latin America in São Paulo, Brazil. Since February 1998 he has been head of the Process and Technology Department of debis humaitá. His research interests include design automation, computer support for cooperative engineering and digital product development.

Dieter Haussmann recieved the Dipl.-Wirtschaftsing. degree from the Oskar von Miller Polytechnikum of Munich in 1972. He started his career as a system analyst in the central software development area of Daimler-Benz AG. From 1980 to 1985 he worked as a consultant and project manager in the field of PPS applications. From 1986 to 1995 he was responsible for methods, systems and standards of Product Documentation of Daimler-Benz. Since 1995 he is working in Brazil as leader of the project NED (Implantation of New Product Documentation) and since 1998 he also leads the area IT for Engineering at debis humaitá. His research interests include product documentation methodology and engineering data management applications in world-wide distributed environments. 